\title{
Diverse cell junctions with unique molecular composition in tissues of a sponge (Porifera)
}

Jennyfer M. Mitchell ${ }^{1,2}$ and Scott A. Nichols ${ }^{1 *}$ (D)

\begin{abstract}
The integrity and organization of animal tissues depend upon specialized protein complexes that mediate adhesion between cells with each other (cadherin-based adherens junctions), and with the extracellular matrix (integrin-based focal adhesions). Reconstructing how and when these cell junctions evolved is central to understanding early tissue evolution in animals. We examined focal adhesion protein homologs in tissues of the freshwater sponge, Ephydatia muelleri (phylum Porifera; class Demospongiae). Our principal findings are that (1) sponge focal adhesion homologs (integrin, talin, focal adhesion kinase, etc.) co-precipitate as a complex, separate from adherens junction proteins; (2) that actin-based structures resembling focal adhesions form at the cell-substrate interface, and their abundance is dynamically regulated in response to fluid shear; (3) focal adhesion proteins localize to both cell-cell and cell-extracellular matrix adhesions, and; (4) the adherens junction protein $\beta$-catenin is co-distributed with focal adhesion proteins at cell-cell junctions everywhere except the choanoderm, and at novel junctions between cells with spicules, and between cells with environmental bacteria. These results clarify the diversity, distribution and molecular composition of cell junctions in tissues of E. muelleri, but raise new questions about their functional properties and ancestry.
\end{abstract}

\section{Introduction}

Beyond simply gluing cells together, cell adhesion molecules are dynamically regulated during development and cell migration, spatially regulated in polarized tissues, and involved in cell signaling and mechanotransduction [1-7]. Consequently, myriad adhesion mechanisms have evolved to function in different contexts in animals (e.g., [8]). Of these, two predominate: (1) the adherens junction, which is involved in cell-cell adhesion and is composed of cadherin receptors, $\mathrm{p} 120-, \alpha$ - and $\beta$-catenin, and (2) focal adhesions, which are involved in cell-extracellular matrix (ECM) adhesion and composed of protein such as integrins, vinculin, paxillin, talin and focal adhesion kinase (FAK).

The molecular components of both the adherens junction and focal adhesions are widely conserved in animals, and some of their components have origins outside of animals [9-13]. However, experimental studies of cell

\footnotetext{
*Correspondence: scott.nichols@du.edu

${ }^{1}$ Department of Biological Sciences, University of Denver, 2101 E. Wesley

Ave. SGM 203, Denver, CO 80208, USA

Full list of author information is available at the end of the article
}

junction composition and function are largely restricted to bilaterian animals, such as the roundworm Caenorhabditis elegans, the fruit fly Drosophila melanogaster, and vertebrates. Recent studies demonstrate conserved roles for adherens junction proteins in cnidarians, as well [14-16].

Organisms of critical importance for reconstructing early steps in the evolution of animal cell adhesion mechanisms are the sponges (Porifera). They are one of the most phylogenetically divergent groups of animals [17, $18]$, their anatomy is fundamentally different from other animals [19], and there are long-standing questions about the structure and homology of their tissues compared to epithelia in other animals $[20,21]$. It has been argued that cell adhesion in sponges (class Demospongiae, in particular) relies primarily upon an extracellular proteoglycan complex termed the Aggregation Factor [22-28]. Antibodies raised against the Aggregation Factor have been reported to block reaggregation of dissociated cells [29], and purified Aggregation Factor can mediate adhesion between beads in cell-free assays [30]. Consequently, the integrity of demosponge tissues is thought to depend upon the interaction of cells with the Aggregation Factor, 
an ECM component, rather than through cell junctions like those found in epithelia of other animals [31,32].

The singular importance of the Aggregation Factor has been challenged by sequencing studies that have revealed conserved homologs of genes encoding adherens junction and focal adhesion proteins in diverse sponges [33-35]. Moreover, there is mounting experimental evidence that these proteins have conserved adhesion roles in sponge tissues. In the homoscleromorph sponge Oscarella pearsei (formerly O. carmela), a homolog of vinculin (common to adherens junction and focal adhesions in bilaterians) was detected at cell-cell and cellECM adhesions, and was found to interact with actin and talin in vitro [36]. Also, a yeast two-hybrid screen revealed conserved interactions between the adherens junction component $\beta$-catenin with a classical cadherin [37]. Likewise, in the freshwater demosponge Ephydatia muelleri, both a classical cadherin and $\alpha$-catenin were detected as co-precipitates of $\beta$-catenin ( $\operatorname{Em} \beta$-catenin), which localized to actin plaques at cell-cell contacts that resemble adherens junctions (Fig. 1) [38]. These data indicate that adherens junction and focal adhesion proteins may have conserved functions in sponge tissues.

However, the study of $\mathrm{Em} \beta$-catenin has also revealed new peculiarities of cell adhesion in demosponges. Cells of the basopinacoderm (the tissue at the interface with the substrate) contain actin bundles that Max Pavans De Ceccatty [39] described as "devices for cell-to-substratum attachment." If the mechanisms of cell-substrate adhesion in sponges are conserved with other animals, one might expect that these are integrin-based focal adhesions. Instead, they were found to stain positive for Em $\beta$-catenin, an adherens junction component [38].

To better understand the composition and organization of cell junctions in demosponge tissues, we examined the endogenous interactions and distribution of the focal adhesion proteins vinculin ( $\mathrm{Vcl})$, focal adhesion kinase (FAK) and integrin- $\beta$ (ITGB) in E. muelleri. We found that this species has diverse adhesion structures composed of adherens junction and focal adhesion proteins, but these proteins are not as strictly partitioned to cellcell versus cell-ECM junctions as they are in epithelial tissues of bilaterian animals. Instead, these proteins are often co-distributed in both contexts. Moreover, E. muelleri has specialized junctions not found in other animals; including cell-spicule junctions and cell-bacteria junctions. These data contribute to an increasingly complex narrative about the ancestral diversity and organization of cell junctions and their roles in early animal tissue evolution.

\section{Results}

BLAST search [40] of the E. muelleri transcriptome [41] revealed highly conserved homologs of the primary protein components of focal adhesions. We detected seven integrin- $\beta$ homologs, six integrin- $\alpha$ homologs, two talin homologs, and one homolog each of vinculin, focal adhesion kinase, and paxillin (Additional files 1,2); integrins were numbered to reflect their relative expression levels, not to indicate their orthology to integrin subfamilies in other animals. We characterized the distribution of select focal adhesion proteins in E. muelleri tissues by

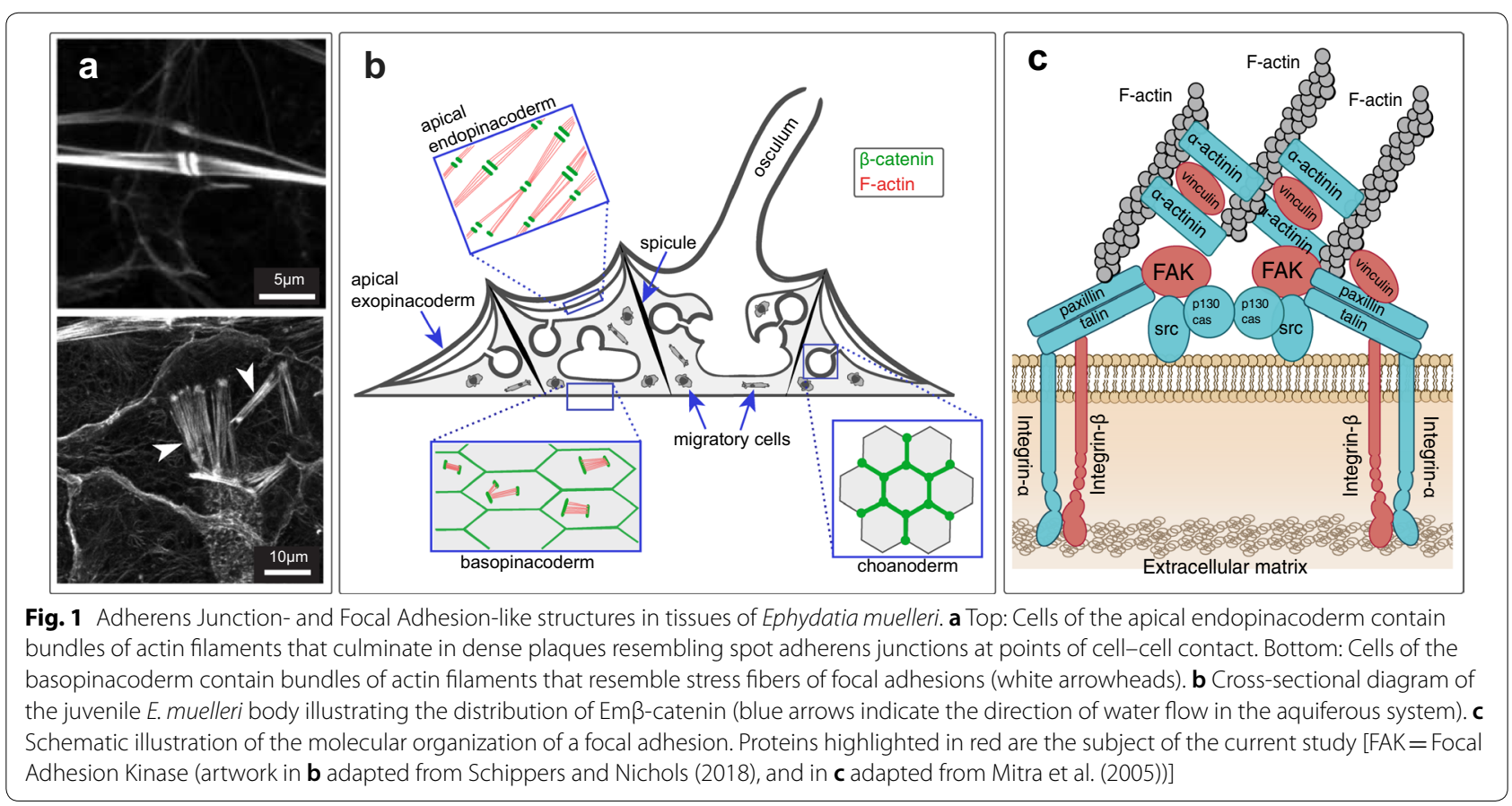


co-immunoprecipitation and immunostaining with custom antibodies against EmVcl, EmFAK and EmITGB1.

\section{Focal adhesion proteins co-precipitate from cell lysates}

To test for conserved functional interactions between focal adhesion homologs in E. muelleri, we used coimmunoprecipitation (co-IP) coupled with liquid chromatography-mass spectrometry (LC-MS/MS) to identify proteins that co-precipitate with EmVcl, EmFAK and EmITGB1 from whole-cell lysates (Fig. 2). Anti$\mathrm{EmVcl}$ recognized a specific band of the expected size by Western Blot of E. muelleri lysates used as input for immunoprecipitation. This band was depleted in the flow-through/unbound fraction and enriched in the precipitate elutions (Fig. 2a). Analysis of the immunoprecipitate identified this protein as $\mathrm{EmVcl}$, and there were few detected co-precipitates (Fig. 2a'; Table 1; Additional file 3). Pre-adsorption of anti-EmVcl with $5 \mu \mathrm{g}$ of the recombinant antigen completely abolished immunostaining signal (Additional file 4: Figure S1).

Anti-EmITGB1 had low affinity for multiple proteins in denatured E. muelleri lysates as detected by Western Blot, none of which matched the expected molecular weight of EmITGB (Fig. 2b). Immunoprecipitation with anti-EmITGB was hindered by cross-linking to the agarose resin, but was successful if the antibody was not cross-linked. Multiple bands were detected by Western Blot of the precipitate, one of which potentially corresponded to the expected size for EmITGB1 in the precipitate, eluted fraction 2. Analysis by LC-MS/MS of the high-molecular weight fraction of EmITGB1 precipitates detected each of EmITGB1, EmITGB2 and EmITGB4. Of these, EmITGB1 was most abundant. This antibody is subsequently referred to anti-EmITGB, generally, to reflect this cross-reactivity with other paralogs.

In contrast to the EmVcl co-IP, many other proteins were detected as co-precipitates of EmITGB1 (Table 1; Additional file 5). The most abundant protein in the sample was EmITGA1 (it was also detected at very low levels in the IgG control). Integrin- $\beta$ is well known to heterodimerize with integrin- $\alpha$, so it is probable that EmITGA1 is highly represented in the sample because it heterodimerizes with the multiple EmITGB paralogs recognized by the antibody. Other than EmITGB, the most highly abundant protein in the precipitate was a phosphodiesterase (possibly PDE8). This protein was nearly equally abundant to EmITGB and has a predicted molecular weight of $\sim 86 \mathrm{kDa}$. PDEs are known regulators of cell adhesion, and direct interactions with integrins have been characterized. Other known focal adhesion proteins detected in the sample include EmFAK, EmTalin2, EmITGA1 and EmITGA3, strongly supporting conserved endogenous interactions between focal adhesion proteins in
E. muelleri. Immunostaining signal was abolished upon preadsorption of anti-EmITGB with $1 \mu \mathrm{g}$ of the injected antigen (Additional file 4: Figure S2).

Figure 2c illustrates that anti-EmFAK recognizes multiples bands in denatured cell lysates by Western Blot, including a band of the expected size. This band was depleted in the flow-through/unbound fraction, and enriched in the precipitate. Like anti-EmITGB, antiEmFAK activity was disrupted by cross-linking, so immunoprecipitates were co-eluted with the uncrosslinked antibody. High-molecular-weight gel slices were used for LC-MS/MS rather than the entire antibody-saturated precipitate. In the fraction analyzed by proteomic analysis, EmFAK was found to be highly enriched in the antiEmFAK precipitate, and absent from the IgG negative control sample (Fig. 2c'; Table 1; Additional file 6). Preadsorption of anti-EmFAK with $10 \mu \mathrm{g}$ of the recombinant antigen fully abolished immunostaining signal (Additional file 4: Figure S1).

These data strongly support that all three antibodies used in this study specifically bind to their expected targets under native conditions in E. muelleri tissues and lysates. Only EmVcl gave robust and specific signal under denaturing conditions (Western Blot). These data also support that EmITGB functions as part of a complex with the focal adhesion proteins EmITGA, EmFAK, EmTalin and EmPDE8 [42]. Neither EmVcl nor EmPaxillin (a constitutive focal adhesion component in bilaterian animals) was detected in precipitates.

\section{Focal adhesion-like structures may function in substrate attachment}

To determine whether focal adhesion-like structures in the basopinacoderm (Fig. 1) are involved in cell-substrate attachment, it was important to distinguish whether they form at the interface between the tissue and the substrate (coverslip), or between the tissue and the mesohyl (ECMfilled interior of the sponge). To test this, we used Total Internal Reflection Fluorescence (TIRF) Microscopy [43, 44] and found that junction-associated stress fibers [45] were within 100-200 $\mathrm{nm}$ of the coverslip, near the substrate-adjacent cell membrane (Fig. 3a) - consistent with a role in cell-substrate attachment. We further reasoned that shear forces associated with water flow and turbulence should lead to an increase in the number of focal adhesion-like structures, as mechanical tissue stress induces focal adhesion formation in cultured vertebrate cells [46]. To test this, we grew sponges in dishes on a rocking platform for comparison with sponges grown in dishes on a stable platform. As shown in Fig. 3b, a $43 \%$ increase was detected in sponges grown on a rocking platform $(n=12, p$ value $=0.0058)$. 


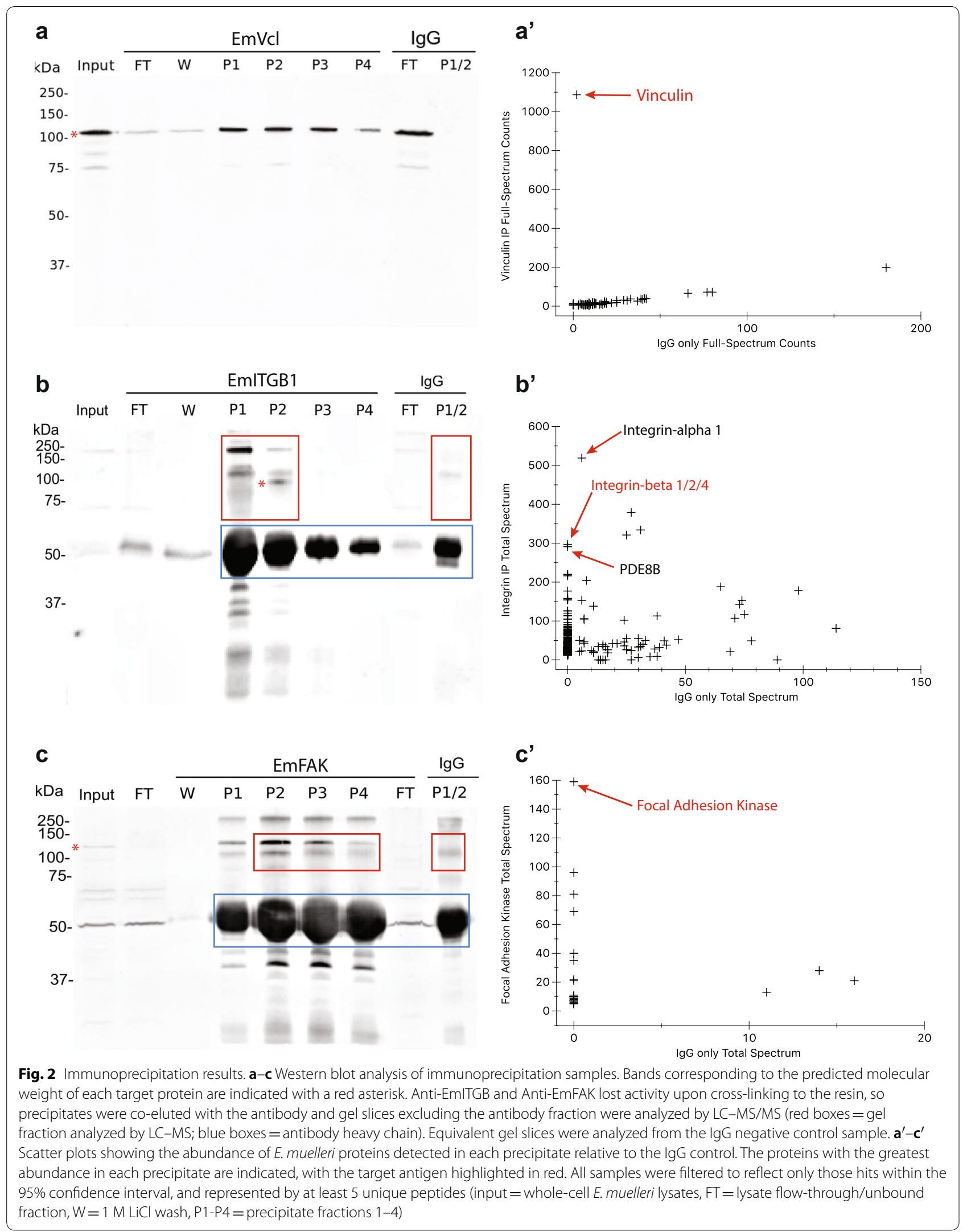


Table 1 Abundance of focal adhesion proteins in immunoprecipitates

\begin{tabular}{llll}
\hline & Precipitate & $\begin{array}{l}\text { Total } \\
\text { spectrum } \\
\text { count IP }\end{array}$ & $\begin{array}{l}\text { Total spectrum } \\
\text { count IgG } \\
\text { control }\end{array}$ \\
\hline Anti-EmVcl & Vinculin & 1087 & 2 \\
Anti-EmITGB1 & Integrin alpha-1 & 519 & 6 \\
& PDE-8 & 291 & 0 \\
& Integrin beta-1 & 220 & 0 \\
& Talin-2 & 84 & 0 \\
& Focal adhesion kinase & 75 & 0 \\
& Integrin beta-4 & 68 & 0 \\
& Integrin alpha-3 & 62 & 0 \\
& Integrin beta-2 & 25 & 0 \\
Anti-EmFAK & Focal adhesion kinase & 159 & 0 \\
\hline
\end{tabular}

Three different types of focal adhesion-like structures in the basopinacoderm

Further examination of focal adhesion-like structures in the basopinacoderm revealed three distinct categories (Fig. 4). The first category included the actin filaments detected by TIRF at the substrate-adjacent cell membrane (Fig. 4a), which we termed 'ventral adhesions'. The second category resembled ventral adhesions, but with one or both ends terminating at a membrane invagination or vesicle-containing bacteria (Fig. 4b). We termed these 'bacterial adhesions'. A third category of actin filaments was found to span vertically from the substrate-adjacent (ventral) cell membrane to the mesohyl-adjacent (dorsal) cell membrane. These actin filaments formed prominent plaques on the dorsal surface of the cell (Fig. 4c) that we termed 'dorsal adhesions'.

Immunostaining of adhesion proteins at these three different categories of focal adhesion-like structures revealed that they were compositionally distinct. Only $\mathrm{EmVcl}$ was found to be associated with ventral adhesions (Fig. 5), whereas both $\mathrm{Em} \beta$-catenin and $\mathrm{EmVcl}$ were consistently detected at bacterial adhesions (Fig. 6), and only EmITGB was detected at dorsal adhesions (Fig. 7). The staining patterns of EmFAK were inconsistent in the basopinacoderm, and difficult to discern due to high levels of cytosolic staining. For example, EmFAK was not usually detected at focal adhesion-like structures (Figs. 5, 6,7 ), except rarely at bacterial adhesions (Additional file 4: Figure S2).

\section{Cell junctions at the spicule interface}

In many sponges, spicules are a unique component of the ECM. Spicules are siliceous skeletal elements that act as tent pole-like tissue supports. Specialized transport cells attach to spicules and move them into position [47] where they are anchored by collagen at rosette-shaped clusters of cells in the basopinacoderm [47].

We consistently detected cell junctions at the interface of cells and spicules, which stained positive for both Em $\beta$-catenin and EmVcl. Again, EmFAK had a low signal-noise ratio, making it difficult to determine if it was present at these structures. EmITGB was not detected (Fig. 8). It was unclear if the cells forming these structures
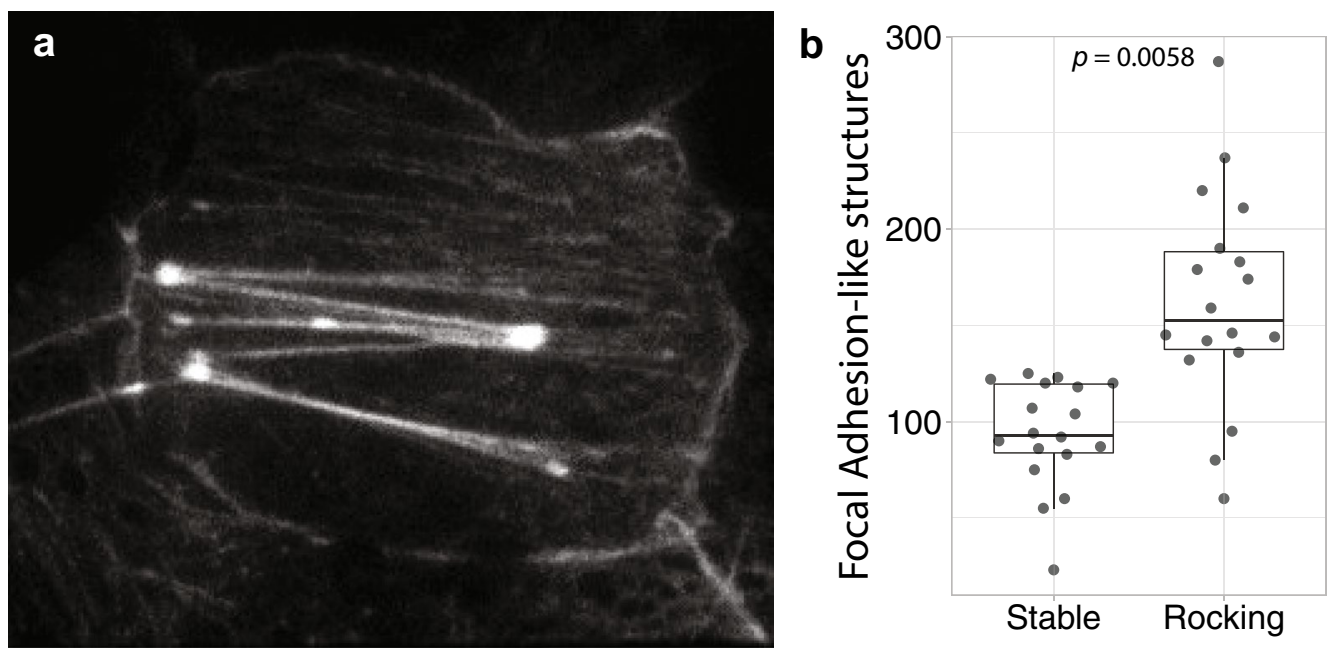

Fig. 3 Actin stress fibers in the basopinacoderm may be associated with cell-substrate adhesions. a Total Internal Reflection Fluorescence (TIRF) imaging was used to determine the subcellular localization of focal adhesion-like structures in the basopinacoderm. $\mathbf{b}$ Their abundance was quantified in individuals grown on a stable surface and compared to individuals grown on a rocking platform 

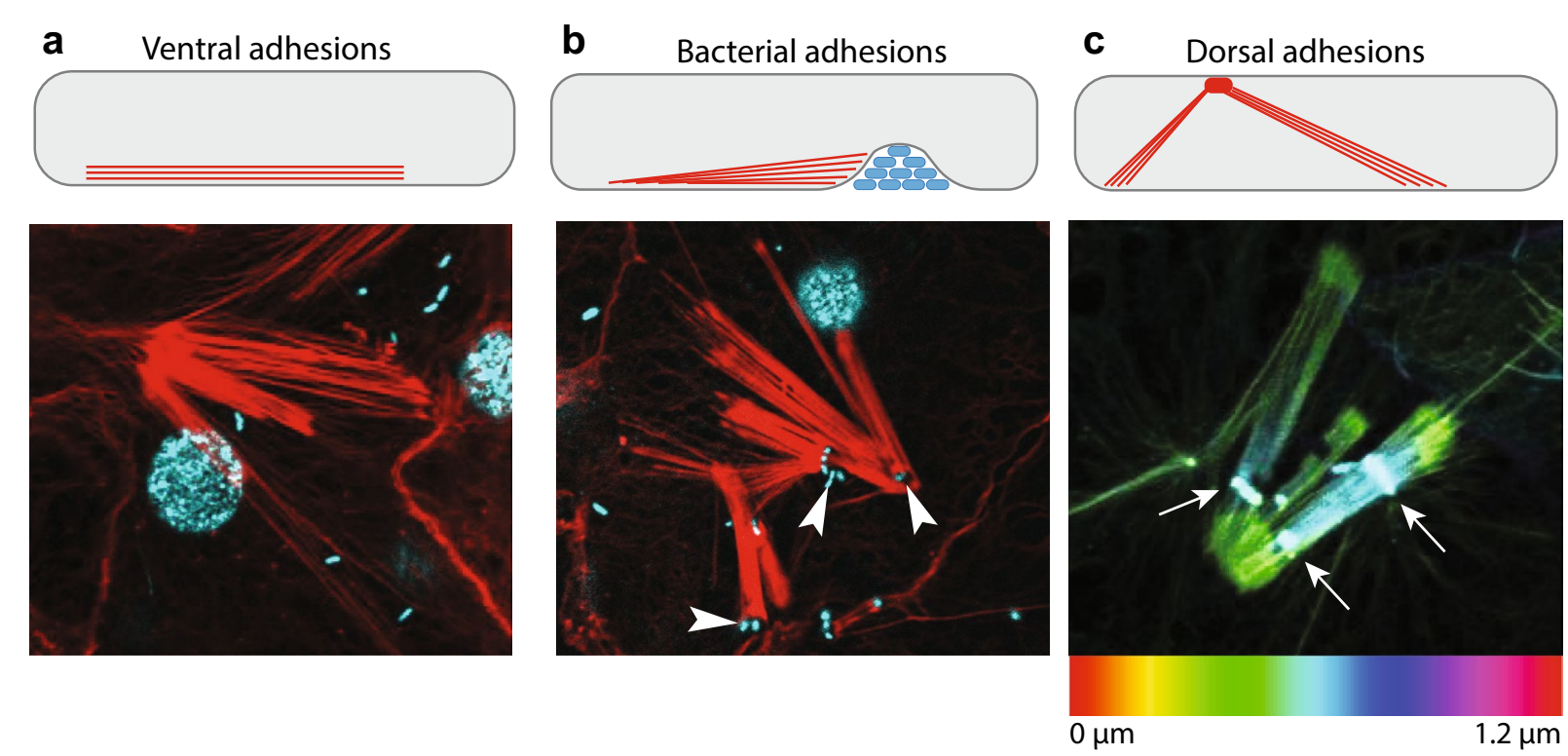

Fig. 4 Three types of focal adhesion-like structures in basopinacoderm. a-c Basopinacocytes (cells of the substrate-attachment epithelium) are drawn at the top in profile view, with the mesohyl interface (dorsal surface) at the top and substrate interface (ventral surface) at the bottom. Bundles of actin filaments were found at $\mathbf{a}$ ventral surface, and $\mathbf{b}$ were sometimes associated with membrane invaginations containing bacteria (white arrowheads). c Actin staining, colored to depict pixel depth within the confocal stack. White arrows indicate dorsal adhesions, from which actin filaments descend ventrally within cell $(\mathbf{a}, \mathbf{b}$ : red $=$ actin; cyan $=\mathrm{DNA})$

were transport cells, basopinacocytes, or a different cell type altogether.

\section{No evidence for focal adhesion-dependent cell migration} Focal adhesions have well-characterized roles in the migration of cultured vertebrate cells, where they provide traction needed for movement across two-dimensional surfaces. However, movement in three-dimensional environments is often less dependent on integrin-mediated adhesion [48]. We have previously shown that migratory cells in the three-dimensional environment of the mesohyl (Video in Additional file 7) of O. pearsei stain positive for vinculin [36], but neither $\mathrm{EmVcl}, \mathrm{EmFAK}$, nor EmITGB was detected in migratory cells of E. muelleri (Additional file 4: Figure S3).

\section{Both $\mathrm{Em} \beta$-catenin and focal adhesion proteins are present at cell-cell junctions}

We previously reported cortical staining of $\mathrm{Em} \beta$-catenin in the basopinacoderm, choanoderm, and the apical endopinacoderm (the inner tissue layer of the sponge surface; see Fig. 1) [38]. As shown in Fig. 5a, Em $\beta$-catenin was again detected at the cell cortex in the basopinacoderm, but we also detected EmVcl (Fig. 5b) and less frequently EmITGB (Additional file 4: Figure S4). This staining was generally of low intensity and patchy, and we wondered whether this might reflect the developmental stage of the immature juvenile tissues examined. To test this, we grew sponges for an additional 3 weeks and found markedly elevated levels of cortical staining and robust adherens junction-like structures that were EmVcl-positive (Additional file 4: Figure S5). This result indicates that low-intensity cortical staining of EmVcl (and other antibodies) may reflect the early developmental stage of the tissues and that cell-cell adhesions strengthen over time.

We detected focal adhesion proteins at cell-cell junctions in other tissues, as well. The most conspicuous cell-cell junctions in E. muelleri are found in the apical endopinacoderm at points where actin tracts align between neighboring cells (Fig. 1b). Em $\beta$-catenin was previously detected at these structures [38], and we found that EmVcl, EmFAK and EmITGB were also constitutively present (Fig. 9). Cortical staining of EmITGB was also detected in an adjacent tissue, the exopinacoderm (Fig. 9d) - this is the outermost tissue and is so close in proximity to the apical endopinacoderm that they cannot be separately resolved by confocal microscopy.

The detection of EmVcl and EmFAK at cell-cell junctions is not unprecedented. Applied force on E-cadherin has been shown to lead to phosphorylation of human vinculin at Y822 and recruitment to the adherens junction $[49,50]$. However, alignment of EmVcl to human vinculin revealed low conservation in the region that 

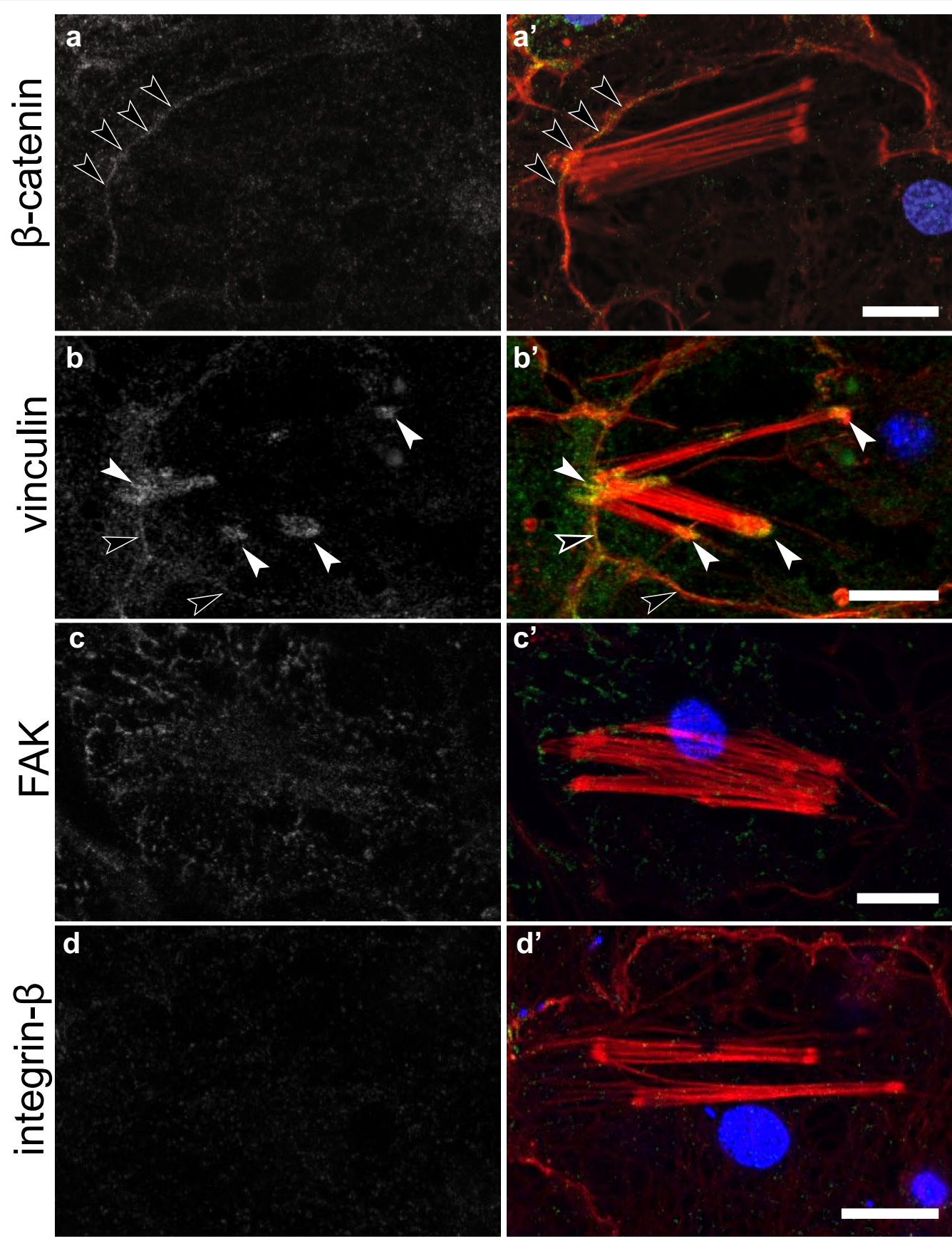

Fig. 5 Immunostaining of ventral adhesions in the basopinacoderm. Both Emß-catenin and EmVcl exhibited faint cell boundary staining (black arrowheads), but only EmVcl was detected in association with ventral adhesions (white arrowheads) (a-d antibody staining only; $\mathbf{a}^{\prime}-\mathbf{d}^{\prime}$ antibody $=$ green, $\mathrm{DNA}=$ blue, actin $=$ red; scale bars $=10 \mu \mathrm{m}$ )

contains Y822 (Additional file 4: Figure S6), making it difficult to predict if this mechanism for regulating vinculin function is conserved in E. muelleri. But, EmVcl was not detected as a co-precipitate of $\mathrm{Em} \beta$-catenin [38], nor did we detect adherens junction proteins as co-precipitates of EmVcl (Additional file 3).
Like vinculin, focal adhesion kinase has also been reported to function in contexts other than focal adhesions, including at the adherens junctions of vascular endothelia, where it directly binds VE-cadherin and phosphorylates $\beta$-catenin in response to VEGF activation [51]. However, EmFAK was not detected as a 


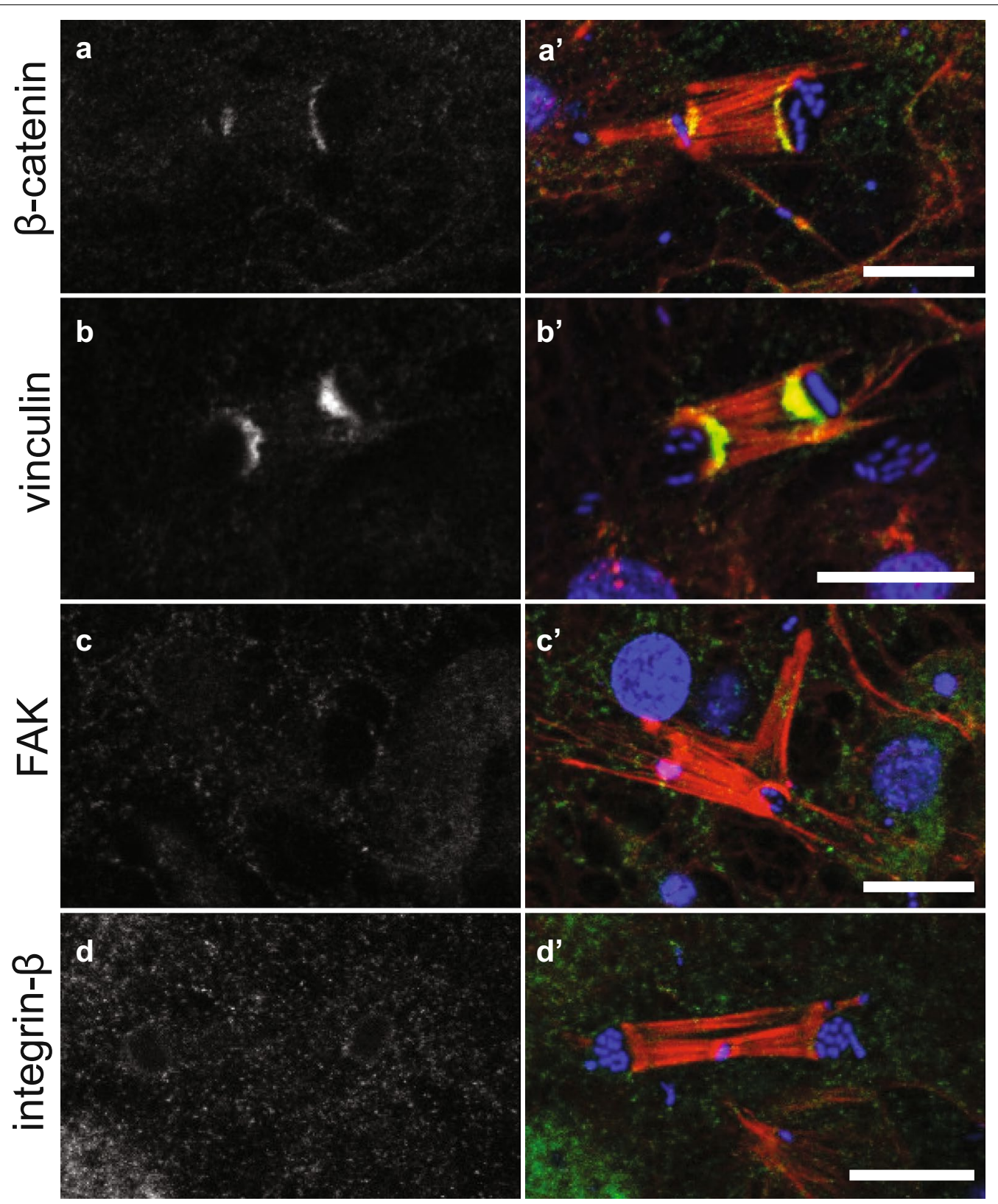

Fig. 6 Immunostaining of bacterial adhesions in the basopinacoderm. Both (a) Emß-catenin and (b) EmVcl were detected at the interface of stress fibers and membrane pockets containing environmental bacteria. Neither (c) EmFAK nor (d) EmITGB were detected at these structures (but see text for further discussion of EmFAK) (a-d antibody staining only; $\mathbf{a}^{\prime}-\mathbf{d}^{\prime}$ antibody $=$ green, DNA = blue, F-actin $=$ red; scale bars $=10 \mu \mathrm{m}$ ]

co-precipitate of $\operatorname{Em} \beta$-catenin [38], whereas it did coprecipitate with EmITGB (Table 1). We treated sponges with 5- $\mu \mathrm{M}$ FAK inhibitor 14 and found that this treatment abolished FAK staining at cell-cell junctions, but detected no other effects on the formation or molecular composition of adhesion structures in the apical endopinacoderm (Additional file 4: Figure S7).

The only tissue where we did not find evidence of co-distributed adherens junction- and focal adhesion proteins at cell-cell contacts was the choanoderm (Additional file 4: Figure S8). In this tissue, $\mathrm{Em} \beta$ catenin alone was detected [38].

\section{Discussion}

Most animal cell adhesion proteins evolved early, concurrently with or before the transition to multicellularity [9, $12,31,34,35,37,52-54]$. However, our understanding of how these proteins functioned ancestrally, and when they 


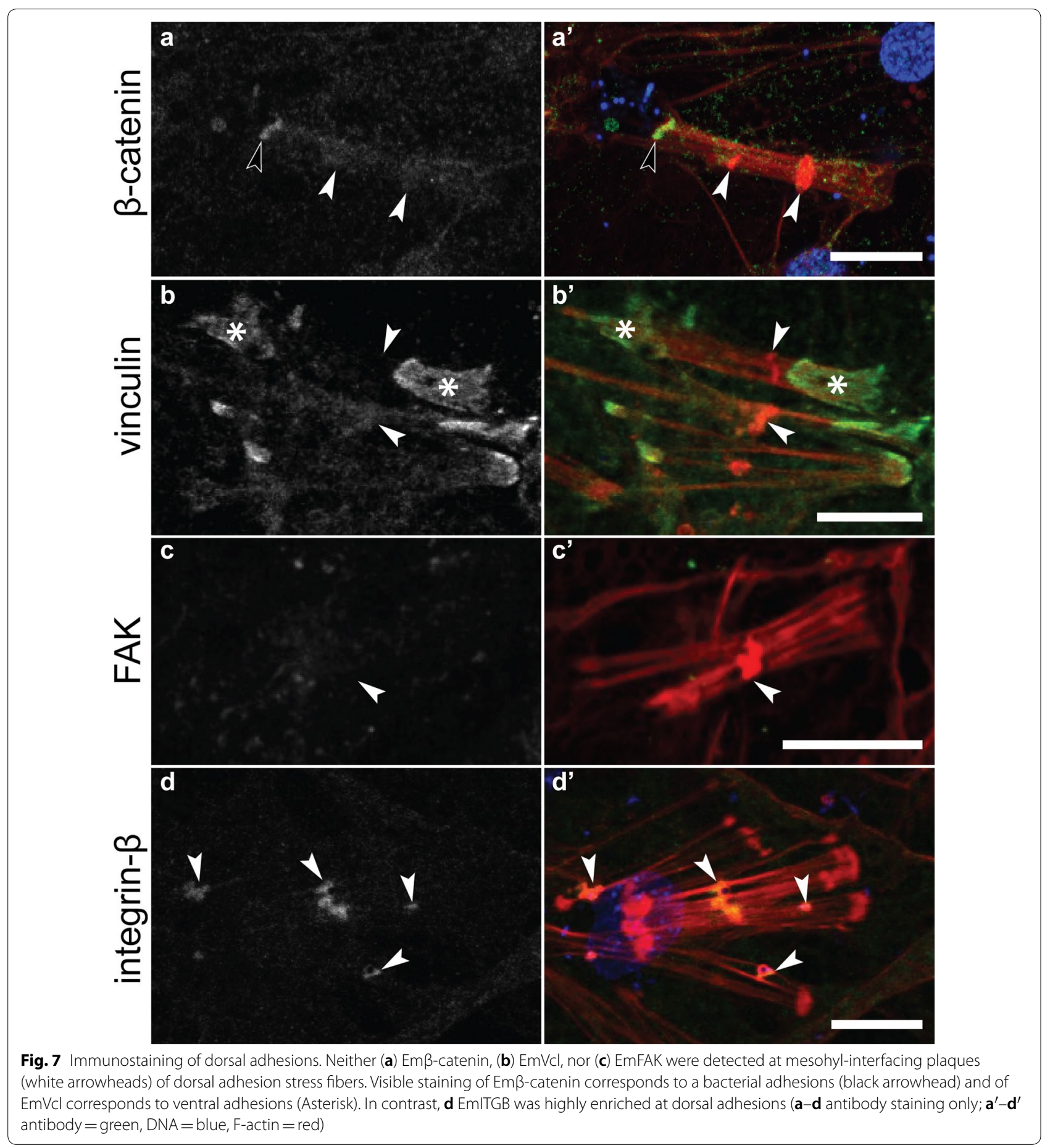

were organized into interacting complexes (i.e., cell junctions) is limited. We examined the interactions and distribution of focal adhesion proteins in tissues of $E$. muelleri. We found that they co-precipitate as a complex from cell lysates and that EmVcl, EmFAK and EmITGB localize to apparent cell junctions, supporting the conclusion that they have conserved adhesion roles. However, we also detected a critical difference in the spatial distribution of these proteins in E. muelleri tissues compared to epithelia in other animals. Rather than being restricted to focal adhesion-like structures at cell-ECM contacts, they were also detected at adherens junction-like structures at cell-cell contacts, and were often co-distributed with the adherens junction protein $\operatorname{Em} \beta$-catenin. 

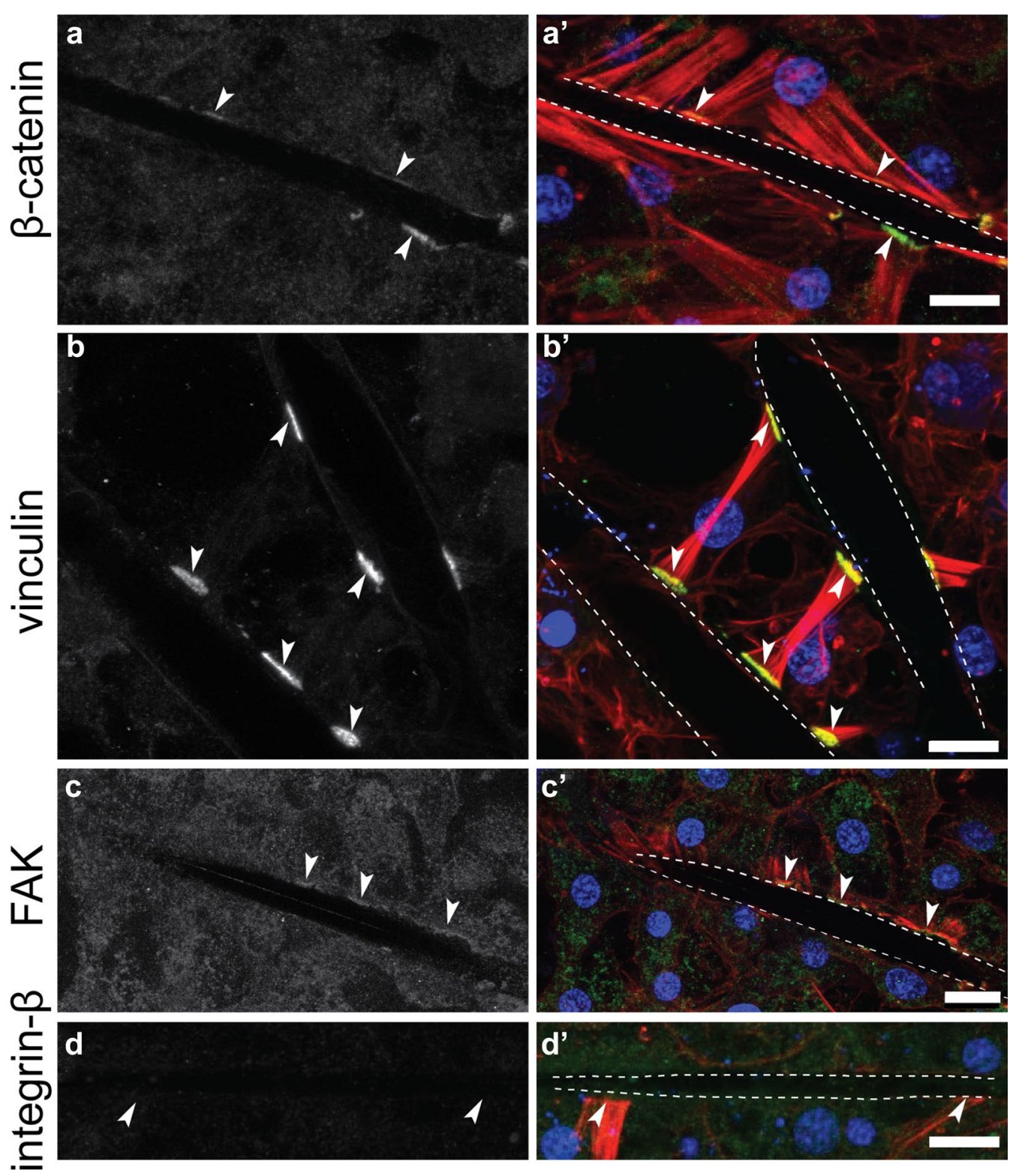

Fig. 8 Immunostaining of cell-spicule junctions. a Emß-catenin and $\mathbf{b}$ EmVcl localize to cell junctions at the interface with spicules (dotted lines mark spicules). c EmFAK was possibly enriched at these structures, but only marginally above background levels (arrowheads), whereas $\mathbf{d}$ EmITGB was not detected at all (a-d antibody staining only; $\mathbf{a}^{\prime}-\mathbf{d}^{\prime}$ antibody $=$ green, DNA = blue, F-actin = red; scale $=10 \mu \mathrm{m}$ )

In a prior study, we reported a similar anomaly: $\operatorname{Em} \beta$ catenin localizes to focal adhesion-like structures in the basopinacoderm of E. muelleri [38]. Here, we found that these structures can be parsed into structurally and compositionally distinct categories: ventral, dorsal, and bacterial adhesions. When taken into consideration, we found that $\operatorname{Em} \beta$-catenin was not actually associated with either ventral or dorsal adhesions. Instead, these structures, respectively, stained positive for $\mathrm{EmVcl}$ and EmITGB, consistent with their homology to focal adhesions in bilaterian tissues. The absence of EmITGB staining at EmVcl-positive adhesions does not necessarily indicate the absence of integrins altogether, as our antibody recognized only three of seven identified paralogs. In the future, the focal adhesion protein talin may serve as a more universal marker of integrin-distribution, as it is constitutively present at all integrin-based adhesions in other animals, and was detected as a co-precipitate of EmITGB from E. muelleri lysates. 


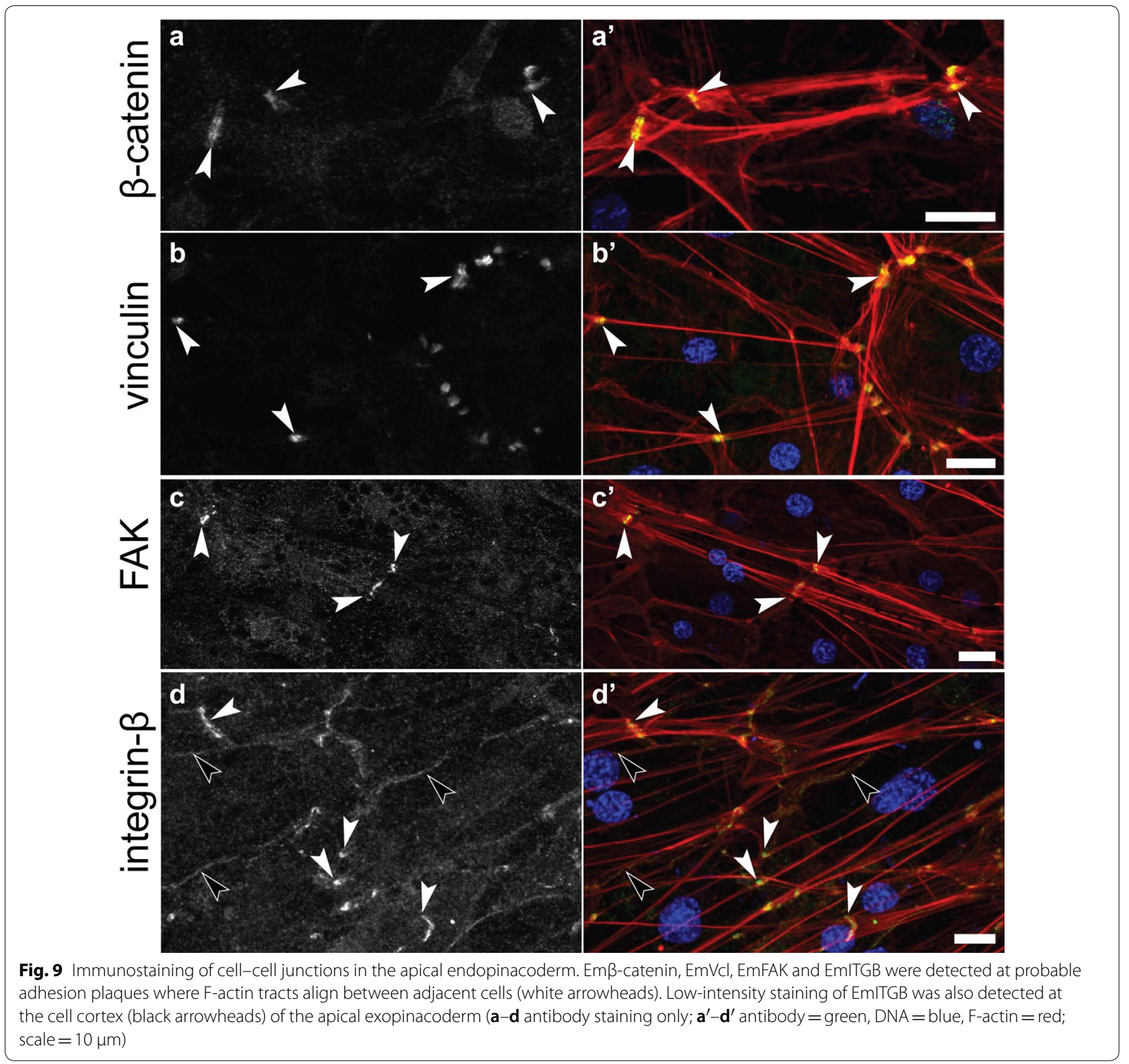

The previously reported $\operatorname{Em} \beta$-catenin staining at focal adhesion-like structures in the basopinacoderm is actually restricted to bacterial adhesions. In this context, $\operatorname{Em} \beta$-catenin is co-distributed with the focal adhesion protein homologs, EmVcl and (sometimes) EmFAK. The functional significance of these junctions is unknown, but intriguing. In natural environments, bacterial biofilms are abundant and often provide settlement cues for the larvae of aquatic animals, including sponges [55]. Thus, it seems plausible that bacterial adhesions could be involved in environmental sensing through integrinmediated signaling. An alternative possibility comes from the observation that the bacteria at these structures are encapsulated in membrane invaginations or vesicles. Most sponge cells are phagocytic [56], and perhaps bacterial adhesions are involved in phagocytosis. This could be an undescribed mode of feeding, or function in the uptake of intracellular symbionts or pathogens. There is precedent for such a mechanism in vertebrates, where integrins are known to be involved in phagocytosis of particles, including microorganisms as part of a pathogen defense system $[57,58]$. A difference is that $\beta$-catenin is not detected at these structures in vertebrates. 
In the future, it will be interesting to identify the bacterial species at these structures, track their fate in sponge cells, and test for bacterial adhesions in attached larvae undergoing metamorphosis. Animals evolved in an environment dominated by bacteria [59], and a compelling hypothesis is that cell adhesion molecules may have first evolved to mediate interactions with bacteria [53].

A mixture of adherens junction and focal adhesion proteins was also detected in adhesion contexts other than bacterial adhesions. Specifically, focal adhesion proteins were co-distributed with $\operatorname{Em} \beta$-catenin at cell-spicule junctions, which essentially have the same composition as bacterial adhesions, and cell-cell junctions. The latter had previously been interpreted as probable adherens junctions [38], but until the role of focal adhesion proteins (particularly integrins) at these structures is clarified, this conclusion is less certain.

The co-distribution of Em $\beta$-catenin with EmVcl, EmFAK and EmITGB could indicate that these proteins are part of a common adhesion complex in E. muelleri tissues, but our immunoprecipitation results do not support this view. Focal adhesion proteins co-precipitate as a complex, just as adherens junctions proteins were found to co-precipitate [38]; each to the exclusion of the other. Also, Em $\beta$-catenin alone was detected at cell-cell contacts in the choanoderm, and focal adhesion proteins alone were detected at ventral and dorsal adhesions in the basopinacoderm. This indicates that these protein complexes are functionally separable and may have discrete roles, even where they are co-distributed.

Full characterization of demosponge cell junctions will require further identification of associated adhesion receptors (e.g., cadherins), and integration of these data with models of Aggregation Factor-mediated cell adhesion. One clue to how these adhesion systems may interact is that the Aggregation Factor has reported RGD motifs, leading to the hypothesis that it may activate integrin signaling [31, 60]. But, the Aggregation Factor has predominantly been studied in vitro, in cell dissociation/ re-aggregation assays. Its distribution is not well characterized in intact tissues.

An important consideration is that, until recently, hypotheses about the evolutionary origin of animal cell adhesion mechanisms have been inadvertently biased toward bilaterian models. As we begin to examine cell adhesion in non-bilaterian lineages, there appears to be more mechanistic diversity than anticipated. For example, the cnidarian Nematostella vectensis has a conserved classical cadherin/catenin complex [16], but $\beta$-catenin is not always detected at cadherin-positive cell-cell adhesions in tissues [15, 61]. Likewise, sequence analyses of ctenophores indicate that they lack conserved cadherin/ $\beta$-catenin interaction motifs [52], and a recent study indicates that $\beta$-catenin is altogether absent at cellcell contacts in Mnemiopsis leidyi [62]. The molecular composition of cell junctions in placozoans is entirely uncharacterized, but from an ultrastructural perspective they resemble adherens junctions [63]. Placozoans altogether lack cell-ECM junctions and a basal lamina [64]. A comprehensive understanding of the timing and sequence of cell junction assembly and the evolution of epithelia will require detailed studies of adhesion in diverse non-bilaterian tissues.

\section{Conclusions}

This study supports that adherens junction and focal adhesion proteins functioned in adhesion and tissue organization in the last common ancestor of sponges and other animals. This stands in apparent contrast to studies which have emphasized the Aggregation Factor as the predominant adhesion mechanism in demosponges. At least in E. muelleri, tissues appear to be organized much more like epithelia in other animals than previously appreciated. However, in contrast to cell adhesion properties that E. muelleri shares in common with other animals, we also discovered new differences. Adherens junction and focal adhesion proteins are not strictly partitioned into compositionally distinct cell-cell and cellECM junctions; rather, they are often co-distributed. Furthermore, the discovery of specialized cell-bacteria junctions raises new questions about the functional significance of these structures for sponge physiology (environmental sensing, feeding, symbiosis, or pathogen defense), and possibly about the ancestral role of cell adhesion molecules in animals. If the interaction of cell adhesion proteins with bacteria is an ancient feature of animal biology, bacterial adhesions in sponges may provide clues to the nature of these interactions.

\section{Materials and methods \\ Identification of focal adhesion protein homologs in $E$. muelleri}

Representative sequences of the focal adhesion proteins integrin- $\alpha$, integrin- $\beta$, vinculin, talin, focal adhesion kinase and paxillin were retrieved from Uniprot [65] and used to query the Ephydatia muelleri transcriptome [41] by BLAST search [66] to identify candidate sponge homologs. The putative domain composition of $E$. muelleri sequences was then annotated using HMMER [67] and SMART [68] web-servers. E. muelleri vinculin was previously distinguished from its close paralog $\alpha$-catenin by phylogenetic analysis [36]. 


\section{Specimens}

Ephydatia muelleri gemmules were collected from "upper" Red Rock Lake, Colorado, USA (40.0802, -105.543 ) in early October. This lake is several hundred meters southwest of Red Rock Lake, Boulder County and is unnamed. Gemmules were stored in autoclaved lake water, in the dark at $4{ }^{\circ} \mathrm{C}$. Before plating, gemmules were washed in $1 \%$ hydrogen peroxide for $5 \mathrm{~min}$, washed three times in autoclaved lake water and grown at room temperature.

\section{Cloning and recombinant protein expression}

The coding sequence of target antigens was amplified by polymerase chain reaction (PCR) from an E. muelleri cDNA library using Phusion High-Fidelity DNA polymerase (NEB). Primer sequences and amplicons are specified in Additional files 1, 2. PCR products were cloned into pET28a (Novagen), pET28 His6 Sumo TEV LIC (1S) \#29659 or pET His6 GST TEV LIC (1G) \#29655 (Addgene) for expression.

Expression constructs were validated by Sanger Sequencing (Eurofins) and transformed into a protease deficient Escherichia coli strain (Rosetta 2(DE3), Promega). For expression, a single colony was grown in Luria Broth at $37{ }^{\circ} \mathrm{C}$ to an $\mathrm{OD}_{600}$ between 0.4 and 0.6 , and then induced with $300 \mathrm{mM}$ of isopropyl-1-thio- $\beta$ D-galactopyranoside (IPTG) for $3-5 \mathrm{~h}$ at $30{ }^{\circ} \mathrm{C}$. Bacterial pellets were collected by centrifugation, resuspended in $1 \times$ PBS pH 7.4 on ice. Cells were lysed by the addition of $1 \mathrm{mg} / \mathrm{mL}$ lysozyme and $0.2 \mathrm{mM}$ phenylmethanesulfonyl fluoride (PMSF), incubation at room temperature (RT) for $15 \mathrm{~min}$, then sonication for $4 \times 30 \mathrm{~s}$. Bacterial debris was removed by centrifugation and the supernatant incubated with either with HisPur Cobalt or Nickel Resin (Thermo Fisher Scientific) for His-tagged proteins or GST-agarose resin (Thermo Fisher Scientific) for GST-tagged proteins, for $\sim 18 \mathrm{~h}$ at $4{ }^{\circ} \mathrm{C}$ on a tube rotator. The resin was collected by centrifugation, and washed in either $1 \times$ PBS pH 7.4 (His-tagged proteins) or $50 \mathrm{mM}$ Tris, $1 \mathrm{M} \mathrm{NaCl}$, pH 8.0 (GST-tagged proteins). After washing, purified recombinant protein was eluted by the addition of either $150 \mathrm{mM}$ imidazole (His-tagged proteins) or $10 \mathrm{mM}$ reduced glutathione (GST-tagged proteins).

\section{Antibody production}

Polyclonal antibodies were generated in rabbit against His-EmVcl, His-EmFAK and GST-EmITGB1 (Syd Labs) recombinant proteins. For affinity purification, two columns were made: (1) whole E. coli lysates, and (2) 6-10 mg of recombinant protein. Each was covalently bound to $1 \mathrm{~mL}$ of AminoLink Plus Coupling resin (Thermo Scientific, Cat\#20501) according to the manufacturer specifications. Anti-sera were passed over the $E$. coli column to remove antibodies against bacterial proteins; then the flow-through was incubated with the antigen-coupled resin for $1 \mathrm{~h}$ at RT under rotation. This column was washed with $12 \mathrm{~mL}$ of AminoLink Wash Buffer and the antibodies were eluted with $500 \mu \mathrm{L}$ $0.1 \mathrm{M}$ glycine $\mathrm{HCl}, \mathrm{pH} 2.5$. The $\mathrm{pH}$ of eluted fractions was adjusted to neutral by adding $30 \mu \mathrm{L}$ of $0.75 \mathrm{M}$ Tris-HCL $\mathrm{pH}$ 9.0. Antibody titer was quantified by spectrophotometry (A280) and by visual comparison to BSA standards via sodium dodecyl sulfate-polyacrylamide gel electrophoresis (SDS/PAGE). The specificity of each antibody was validated by Western Blot, Immunoprecipitation coupled with LC-MS/MS, and by pre-adsorption with the injected antigen prior to immunostaining.

\section{Western Blot}

For each Western Blot, 100 gemmules were grown in petri dishes with lake water containing $100 \mu \mathrm{g} / \mathrm{mL}$ ampicillin for 6-13 days at RT. Juveniles were scraped with a razor into $4 \times$ SDS-PAGE reducing loading buffer $(1 \mathrm{M}$ Tris, pH 7.0, 20\% SDS, 20\% Glycerol, 0.02\% bromophenol blue and $2.5 \% \quad \beta$-mercaptoethanol), vortexed and boiled at $95{ }^{\circ} \mathrm{C}$ for $3 \mathrm{~min}$. Proteins were separated by SDS-PAGE on a $10-12 \%$ gel, and transferred to a PVDF membrane (Millipore) at $350 \mathrm{mAmp}$ for $30 \mathrm{~min}$. Membranes were blocked for $1 \mathrm{~h}$ at RT in 5\% nonfat milk in $1 \times$ PBST, pH 7.4 (0.05\% Tween 20) and then incubated with affinity purified antibodies $(1 \mathrm{mg} / \mathrm{mL}$ stocks) against EmVcl (1:3000), EmFAK (1:1000) and EmITGB (1:1500), in blocking solution for $1 \mathrm{~h}$ at RT and washed twice in $1 \times$ PBST pH 7.4. After $45 \mathrm{~min}$ of incubation with the secondary antibody (Alexa $488^{\circledR}$ Goat Anti-Rabbit IgG Antibody; Life Technologies, 1:1000 dilution) at RT, membranes were washed in $1 \times$ PBST pH 7.4 and imaged using the Molecular Imager FX ProPlus (BioRad).

\section{Immunoprecipitation and mass spectrometry}

Affinity-purified antibodies were coupled to agarose A/G using the Pierce Crosslink CoIP Kit (Thermo Scientific Cat \#26147). A control IP was performed using rabbit IgG (I5006, Sigma-Aldrich). For EmVcl, cell lysates were prepared by combining $1.1 \mathrm{mg}$ of frozen adult tissues with $1.8 \mathrm{~mL}$ Pierce Lysis buffer (Thermo Fisher Scientific) containing Complete Mini Protease Inhibitor Cocktail (Roche, EDTA-free), Aprotinin and Leupeptin (1 mM). Lysates for EmFAK and EmITGB1 IPs were prepared by scraping 300-week-old sponges into $1 \mathrm{~mL}$ Triton Lysis Buffer [TLB; 20 mM HEPES, pH7.4, 150 mM NaCl, 1 mM ethylene glycol tetraacetic acid (EDTA), 10\% Glycerol, 1\% Triton X-100, $1 \mathrm{mM}$ PMSF, $1 \mathrm{mM}$ DTT, protease Inhibitor cocktail (ROCHE), $1 \mathrm{mM}$ Aprotinin, $1 \mathrm{mM}$ Leupeptin]. Different tissue sources and lysis buffers were used 
as the technique was optimized over the course of the project. Samples were vortexed $15 \mathrm{~s}$ and returned to ice for $2 \mathrm{~min}$; this was repeated 3 times. Samples were further homogenized by hand (Argos Tech. A0001) for $30 \mathrm{~s}$, and debris and gemmules were removed via centrifugation at $13,000 \times g$ for $10 \mathrm{~min}$ at $4{ }^{\circ} \mathrm{C} .350 \mu \mathrm{L}$ of the lysate was diluted with an additional $200 \mu \mathrm{L}$ of lysis buffer and combined with the antibody-coupled agarose at $4{ }^{\circ} \mathrm{C}$ for $1.5 \mathrm{~h}$. After collecting the flow-through (FT) and completing the washes recommended by the manufacturer, an extra wash using $1 \mathrm{M} \mathrm{LiCl}$ solution was performed to remove any non specific proteins. Finally, precipitates were eluted with Pierce Low pH Elution Buffer (Cat\#21004, ThermoFisher) and neutralized with $1 \mathrm{M}$ Tris-HCl pH 9.0 (Cat\#42020208-1, Bioworld). 20-25 $\mu \mathrm{L}$ aliquots of these precipitates were mixed with $5 \mu \mathrm{L} 4 \times$ SDS-PAGE loading buffer containing freshly added $20 \%$ 2-mercaptoethanol (BME), boiled for $3 \mathrm{~min}$, and then loaded on a $12 \%$ gel for SDS-PAGE. One gel was used for Coomassie staining, and a replicate was analyzed by Western blot.

EmVcl precipitates were directly sent for further analysis by LC-MS/MS. EmFAK and EmITGB1 precipitates were excised from an SDS-PAGE gel to separate the precipitate from the co-eluted antibody. LC-MS/MS was performed by the Proteomics Core Facility, University of California, Davis for EmVcl and CU-Anschutz Proteomics Core Facility for EmFAK and EmITGB1. Results were analyzed using the software Scaffold (v3.1).

\section{Immunostaining}

Ephydatia muelleri juveniles were grown from gemmules for 5-7 days on No. 1.5 uncoated dishes (MatTEK) or on glass coverslips. Tissues were fixed in $4 \%$ Formaldehyde in $95 \%$ cold $\mathrm{EtOH}$ for $30 \mathrm{~min}-1 \mathrm{~h}$ at $4{ }^{\circ} \mathrm{C}$. Juveniles were then washed three times with $1 \times \mathrm{PBS} \mathrm{pH} 7.6$, and incubated in blocking buffer (3\% BSA in $1 \times$ PBST pH 7.4) overnight at $4{ }^{\circ} \mathrm{C}$. All antibody preparations were titrated to determine their optimal working concentration, from 1:250 to 1:5000. After incubation, samples were washed three times with $1 \times$ PBST and then incubated for $45 \mathrm{~min}$ with secondary antibody (Alexa488 ${ }^{\circledR}$ Goat Anti-Rabbit IgG Antibody; Life Technologies, 1:500 dilution), plus Alexa Fluor568 ${ }^{\circledR}$ Phalloidin (Life Technologies, 1:80) and Hoechst $(33,342,1 \mu \mathrm{g} / \mathrm{mL})$ at RT. Samples were washed once in $1 \times$ PBST and twice in $1 \times$ PBS pH 7.6 and preserved for imaging using anti-fade mounting medium (0.1 M Propyl gallate, $1 \times$ PBS pH 7.6 and 90\% glycerol). Confocal Images were acquired on an Olympus Fluoview FV3000 confocal laser scanning microscope using either a $20 \times / 0.85 \mathrm{NA}, 60 \times / 1.4 \mathrm{NA}$ or $100 \times / 1.4 \mathrm{NA}$ objectives, and processed using FIJI [69]. Neither brightness nor contrast was adjusted in the antibody channel. Immunostaining results were validated by secondary-only control and by pre-incubating each antibody with its corresponding antigen for at least $1 \mathrm{~h}$ at $4{ }^{\circ} \mathrm{C}$ before staining (Additional file 4: Figure S1).

\section{Quantification of focal adhesion abundance}

Single gemmules $(n=12)$ from E. muelleri were placed in $3 \mathrm{~mL}$ of lake water in No. 1.5 uncoated dishes (MatTEK) and allowed to attach ( 3 days). After attachment half were transferred to a rocking platform for $24 \mathrm{~h}$, while the others were left on a steady surface. All individuals were fixed and stained with anti-EmVcl and phalloidin, and the basopinacoderm imaged as described. Focal adhesionlike structures were counted in each of three image stacks per individual and their abundance in each treatment was analyzed using a one-way ANOVA with single factor of treatment in R studio [70].

\section{Pharmacological inhibition of FAK}

Five-day-old juveniles were treated with $5 \mu \mathrm{M}$ FAK Inhibitor 14 (Sigma-Aldrich) for $4 \mathrm{~h}$ at RT in the dark. Treatment was removed and tissues were immediately fixed, immunostained, and imaged as described. The effects of FAK inhibition on cell motility are described in the Additional file 4: Figure S7.

\section{Supplementary information}

Supplementary information accompanies this paper at https://doi. org/10.1186/s13227-019-0139-0.

Additional file 1. DNA transcripts of E. muelleri focal adhesion homologs Additional file 2. Predicted peptide sequences of E. muelleri focal adhesion homologs

Additional file 3. EmVcl colP results

Additional file 4. Supplementary Figures

Additional file 5. EmITGB1 colP results

Additional file 6. EmFAK colP results

Additional file 7. Timelapse video of migratory cells within the mesohyl

Acknowledgements

The authors would like to thank Jeff Colgren for thoughtful discussions and critical input throughout the course of the project.

\section{Authors' contributions}

JM and SN were involved in all aspects of experimental design, data analysis and interpretation, and writing of the manuscript. JM performed protein expression and purification, antibody affinity purification and immunoprecipitation, drug treatments, and immunostaining/imaging. SN performed also performed immunostaining/imaging. Both authors read and approved the final manuscript.

Funding

This work was supported by NASA Grant 16-EXO16_2-0041 (S.A.N.). 


\section{Availability of data and materials}

Sequences and accession numbers for all genes and proteins analyzed in this study are made available in the online Supplement. Custom antibodies are available on reasonable request.

\section{Consent for publication}

Not applicable.

\section{Competing interests}

The authors declare that they have no competing interests.

\section{Author details}

1 Department of Biological Sciences, University of Denver, 2101 E. Wesley Ave. SGM 203, Denver, CO 80208, USA. ${ }^{2}$ Present Address: University of Colorado, Anschutz Medical Campus, 12801 E. 17th Ave. RC1S, 11401G, Aurora, CO 80045, USA.

Received: 16 July 2019 Accepted: 19 September 2019 Published online: 29 October 2019

\section{References}

1. Halbleib JM, Nelson WJ. Cadherins in development: cell adhesion, sorting, and tissue morphogenesis. Genes Dev. 2006;20:3199-214.

2. Collins $C$, Nelson WJ. Running with neighbors: coordinating cell migration and cell-cell adhesion. Curr Opin Cell Biol. 2015;36:62-70.

3. Hynes RO. Cell-matrix adhesion in vascular development. J Thromb Haemost 2007:5:32-40.

4. Zaman MH. Cell adhesion \& migration. Cell Adh Migr. 2008;2:53-4.

5. Kuo J-C. Mechanotransduction at focal adhesions: integrating cytoskeletal mechanics in migrating cells. J Cell Mol Med. 2013;17:704-12.

6. Hynes RO. Integrins: versatility, modulation, and signaling in cell adhesion. Cell. 1992;69:11-25.

7. Pinheiro D, Bellaïche Y. Mechanical force-driven adherens junction remodeling and epithelial dynamics. Dev Cell. 2018;47:391.

8. Ebnet K. Junctional Adhesion Molecules (JAMs): cell adhesion receptors with pleiotropic functions in cell physiology and development. Physiol Rev. 2017;97:1529-54

9. Sebé-Pedrós A, Roger AJ, Lang FB, King N, Ruiz-Trillo I. Ancient origin of the integrin-mediated adhesion and signaling machinery. Proc Natl Acad Sci USA. 2010;107:10142-7.

10. Grau-Bové X, Torruella G, Donachie S, Suga H, Leonard G, Richards TA, et al. Dynamics of genomic innovation in the unicellular ancestry of animals. Elife. 2017. https://doi.org/10.7554/elife.26036

11. Grimson MJ, Coates JC, Reynolds JP, Shipman M, Blanton RL, Harwood AJ. Adherens junctions and $\beta$-catenin-mediated cell signalling in a nonmetazoan organism. Nature. 2000:408:727-31.

12. Dickinson DJ, Nelson WJ, Weis WI. A polarized epithelium organized by beta- and alpha-catenin predates cadherin and metazoan origins. Science. 2011:331:1336-9.

13. Murray PS, Zaidel-Bar R. Pre-metazoan origins and evolution of the cadherin adhesome. Biol Open. 2014:3:1183-95.

14. Clarke DN, Lowe CJ, James Nelson W. The cadherin-catenin complex is necessary for cell adhesion and embryogenesis in Nematostella vectensis. Dev Biol. 2019;447:170-81.

15. Pukhlyakova E, Kirillova A, Kraus Y, Technau U. Cadherin switch marks germ layer formation in the diploblastic sea anemone Nematostella vectensis. Biorxiv, http://dx.doi.org/10.1101/488270.

16. Clarke DN, Miller PW, Lowe CJ, Weis WI, Nelson WJ. Characterization of the cadherin-catenin complex of the sea anemone nematostella vectensis and implications for the evolution of metazoan cell-cell adhesion. Mol Biol Evol. 2016;33:2016-29.

17. Simion P, Philippe H, Baurain D, Jager M, Richter DJ, Di Franco A, et al. A large and consistent phylogenomic dataset supports sponges as the sister group to all other animals. Curr Biol. 2017;27:958-67.

18. King $\mathrm{N}$, Rokas $\mathrm{A}$. Embracing uncertainty in reconstructing early anima evolution. Curr Biol. 2017:27:R1081-8.

19. Leys SP, Hill A. The physiology and molecular biology of sponge tissues. Adv Mar Biol. 2012:62:1-56.
20. Tyler S. Epithelium — the primary building block for metazoan complexity. Integr Comp Biol. 2003;43:55-63.

21. Leys SP, Nichols SA, Adams EDM. Epithelia and integration in sponges. Integr Comp Biol. 2009;49:167-77

22. Humphreys T. Chemical dissolution and in vitro reconstruction of sponge cell adhesions. I. Isolation and functional demonstration of the components involved. Dev Biol. 1963:8:27-47.

23. Cauldwell CB, Henkart P, Humphreys T. Physical properties of sponge aggregation factor. A unique proteoglycan complex. Biochemistry. 1973;12:3051-5.

24. Henkart P, Humphreys S, Humphreys T. Characterization of sponge aggregation factor. Unique proteoglycan complex. Biochemistry. 1973; 12:3045-50

25. Haseley SR, Vermeer HJ, Kamerling JP, Vliegenthart JFG. Carbohydrate selfrecognition mediates marine sponge cellular adhesion. Proc Natl Acad Sci. 2001:98:9419-24.

26. Bucior I, Burger MM. Carbohydrate-carbohydrate interaction as a major force initiating cell-cell recognition. Glycoconj J. 2004:21:111-23.

27. Vilanova E, Santos GRC, Aquino RS, Valle-Delgado JJ, Anselmetti D, Fernàndez-Busquets $X$, et al. Carbohydrate-Carbohydrate interactions mediated by sulfate esters and calcium provide the cell adhesion required for the emergence of early metazoans. J Biol Chem. 2016:291:9425-37.

28. Grice LF, Gauthier MEA, Roper KE, Fernàndez-Busquets X, Degnan SM, Degnan BM. Origin and evolution of the sponge aggregation factor gene family. Mol Biol Evol. 2017;34:1083-99.

29. Schütze J, Krasko A, Diehl-Seifert B, Müller WE. Cloning and expression of the putative aggregation factor from the marine sponge Geodia cydonium. J Cell Sci. 2001;114(Pt 17):3189-98.

30. Jarchow J, Burger MM. Species-specific association of the cell-aggregation molecule mediates recognition in marine sponges. Cell Adhes Commun. 1998;6:405-14.

31. Harwood A, Coates JC. A prehistory of cell adhesion. Curr Opin Cell Biol. 2004;16:470-6.

32. Varner JA. Cell adhesion in sponges: potentiation by a cell surface $68 \mathrm{kDa}$ proteoglycan-binding protein. J Cell Sci. 1995;108(Pt 9):3119-26.

33. Srivastava M, Simakov O, Chapman J, Fahey B, Gauthier MEA, Mitros $\mathrm{T}$, et al. The Amphimedon queenslandica genome and the evolution of animal complexity. Nature. 2010;466:720-6.

34. Fahey B, Degnan BM. Origin of animal epithelia: insights from the sponge genome. Evol Dev. 2010;12:601-17.

35. Nichols SA, Dirks W, Pearse JS, King N. Early evolution of animal cell signaling and adhesion genes. Proc Natl Acad Sci USA. 2006;103:12451-6.

36. Miller PW, Pokutta S, Mitchell JM, Chodaparambil JV, Clarke DN, Nelson WJ, et al. Analysis of a vinculin homolog in a sponge (phylum Porifera) reveals that vertebrate-like cell adhesions emerged early in animal evolution. J Biol Chem. 2018:293:11674-86.

37. Nichols SA, Roberts BW, Richter DJ, Fairclough SR, King N. Origin of metazoan cadherin diversity and the antiquity of the classical cadherin/ $\beta$ catenin complex. Proc Natl Acad Sci USA. 2012;109:13046-51.

38. Schippers KJ, Nichols SA. Evidence of signaling and adhesion roles for $\beta$-catenin in the sponge Ephydatia muelleri. Mol Biol Evol. 2018:35:1407-21

39. DeCeccatty MP. Cytoskeletal organization and tissue patterns of epithelia in the sponge Ephydatia mülleri. J Morphol. 1986;189:45-65.

40. Altschul SF. BLAST algorithm. eLS. 2014. https://doi.org/10.1002/97804 70015902.a0005253.pub2.

41. Peña JF, Alié A, Richter DJ, Wang L, Funayama N, Nichols SA. Conserved expression of vertebrate microvillar gene homologs in choanocytes of freshwater sponges. Evodevo. 2016:7:13.

42. Horton ER, Humphries JD, James J, Jones MC, Askari JA, Humphries MJ. The integrin adhesome network at a glance. J Cell Sci. 2016:129:4159-63.

43. Axelrod D. Cell-substrate contacts illuminated by total internal reflection fluorescence. J Cell Biol. 1981:89:141-5.

44. Fish KN. Total internal reflection fluorescence (TIRF) microscopy. Curr Protoc Cytometry. 2009. https://doi.org/10.1002/0471142956.cy1218s50.

45. Livne A, Geiger B. The inner workings of stress fibers - from contractile machinery to focal adhesions and back. J Cell Sci. 2016;129:1293-304.

46. Davies PF, Robotewskyj A, Griem ML. Quantitative studies of endothelial cell adhesion Directional remodeling of focal adhesion sites in response to flow forces. J Clin Invest. 1994:93:2031-8. 
47. Nakayama S, Arima K, Kawai K, Mohri K, Inui C, Sugano W, et al. Dynamic transport and cementation of skeletal elements build up the pole-andbeam structured skeleton of sponges. Curr Biol. 2015;25:2549-54

48. Paluch EK, Aspalter IM, Sixt M. Focal adhesion-independent cell migration. Annu Rev Cell Dev Biol. 2016;32:469-90.

49. Mui KL, Chen CS, Assoian RK. The mechanical regulation of integrin-cadherin crosstalk organizes cells, signaling and forces. J Cell Sci. 2016;129:1093-100

50. Bays JL, Peng $X$, Tolbert CE, Guilluy C, Angell AE, Pan Y, et al. Vinculin phosphorylation differentially regulates mechanotransduction at cell-cell and cell-matrix adhesions. J Cell Biol. 2014;205:251-63.

51. Chen XL, Nam J-O, Jean C, Lawson C, Walsh CT, Goka E, et al. VEGF-induced vascular permeability is mediated by FAK. Dev Cell. 2012;22:146-57.

52. Belahbib H, Renard E, Santini S, Jourda C, Claverie J-M, Borchiellini C, et al. New genomic data and analyses challenge the traditional vision of animal epithelium evolution. BMC Genomics. 2018;19:393.

53. Abedin M, King N. The premetazoan ancestry of cadherins. Science. 2008;319:946-8

54. Abedin M, King N. Diverse evolutionary paths to cell adhesion. Trends Cell Biol. 2010;20:734-42.

55. Whalan S, Webster NS. Sponge larval settlement cues: the role of microbial biofilms in a warming ocean. Scientific Reports. 2015;4. https://doi. org/10.1038/srep04072.

56. Wilkinson CR, Garrone R, Vacelet J. Marine sponges discriminate between food bacteria and bacterial symbionts: electron microscope radioautography and in situ evidence. Proc R Soc Lond B. 1984;220:519-28.

57. Dupuy AG, Caron E. Integrin-dependent phagocytosis—spreading from microadhesion to new concepts. J Cell Sci. 2008;121:1773-83.

58. Underhill DM, Ozinsky A. Phagocytosis of microbes: complexity in action. Annu Rev Immunol. 2002:20:825-52.

59. Alegado RA, King N. Bacterial influences on animal origins. Cold Spring Harb Perspect Biol. 2014;6:a016162
60. Fernàndez-Busquets X, Gerosa D, Hess D, Burger MM. Accumulation in marine sponge grafts of the mRNA encoding the main proteins of the cell adhesion system. J Biol Chem. 1998;273:29545-53.

61. Salinas-Saavedra M, Rock AQ, Martindale MQ. Germ layer-specific regulation of cell polarity and adhesion gives insight into the evolution of mesoderm. Elife. 2018;7. https://doi.org/10.7554/elife.36740.

62. Salinas-Saavedra M, Wikramanayake A, Martindale MQ. $\beta$-catenin has an ancestral role in cell fate specification but not cell adhesion. Biorxiv, http://dx.doi.org/10.1101/520957.

63. Smith CL, Reese TS. Adherens junctions modulate diffusion between epithelial cells in trichoplax adhaerens. Biol Bull. 2016;231:216-24.

64. Hynes RO. The evolution of metazoan extracellular matrix. J Cell Biol. 2012;196:671-9.

65. UniProt Consortium. UniProt: a worldwide hub of protein knowledge. Nucleic Acids Res. 2019;47:D506-15.

66. Basic Altschul S. Local alignment search tool. J Mol Biol. 1990;215:403-10.

67. Finn RD, Clements J, Eddy SR. HMMER web server: interactive sequence similarity searching. Nucleic Acids Res. 2011;39(Web Server issue):W29-37.

68. Letunic I, Bork P. 20 years of the SMART protein domain annotation resource. Nucleic Acids Res. 2018;46:D493-6.

69. Schindelin J, Arganda-Carreras I, Frise E, Kaynig V, Longair M, Pietzsch T, et al. Fiji: an open-source platform for biological-image analysis. Nat Methods. 2012;9:676-82.

70. RStudio Team. RStudio: Integrated Development for R. RStudio, Inc., Boston, MA. 2015. http://www.rstudio.com/.

\section{Publisher's Note}

Springer Nature remains neutral with regard to jurisdictional claims in published maps and institutional affiliations.
Ready to submit your research? Choose BMC and benefit from:

- fast, convenient online submission

- thorough peer review by experienced researchers in your field

- rapid publication on acceptance

- support for research data, including large and complex data types

- gold Open Access which fosters wider collaboration and increased citations

- maximum visibility for your research: over $100 \mathrm{M}$ website views per year

At BMC, research is always in progress.

Learn more biomedcentral.com/submissions 